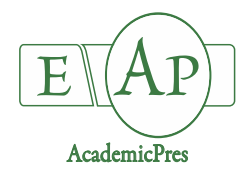

Xu W et al. (2020)

Notulae Botanicae Horti Agrobotanici Cluj-Napoca 48(2):572-587

DOI: $10.15835 /$ nbha 48211946

Research Article

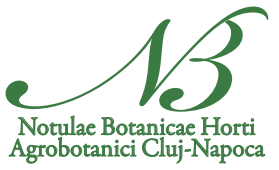

\title{
Somatic embryo induction and Agrobacterium-mediated transformation of embryonic callus tissue in Phoebe bournei, an endangered woody species in Lauraceae
}

\author{
Wenting XU, Miao ZHANG, Chen WANG, Xiongzhen LOU, \\ Xiao HAN, Junhong ZHANG, Yuting ZHANG, Zaikang TONG*
}

\author{
Zhejiang A \& F University, State Key Laboratory of Subtropical Silviculture, Lin'an, Hangzhou, 311300, China; \\ xuwenting_1128@126.com; zhangmiao_0618@126.com;260980198@qq.com; 646352766@qq.com; hanx2017@zafu.edu.cn; \\ zjh6719036@163.com; zhangyutingly@126.com; zktong@zafu.edu.cn ("*orrespondingauthor)
}

\begin{abstract}
Phoebe bournei, a plant species endemic to China, is a precious timber tree and widely used in landscaping. This tree contains numerous secondary metabolites, underscoring its potential economic value. However, studies on this species, including molecular genetic research, remain limited. In this study, both a somatic embryogenesis (SE) technical system and Agrobacterium-mediated genetic transformation were successfully employed in $P$. bournei for the first time. The SE technical system was constructed using immature embryos as original material. The primary embryo and embryonic callus induction rates were $30.66 \%$ and $41.67 \%$, respectively. The highest rate of embryonic callus proliferation was 3.84 . The maximum maturity coefficient and germination rate were 53.44/g and 39\%, respectively. Agrobacterium-mediated genetic transformation was performed using the SE technical system, and the highest transformation rate was $11.24 \%$. The results presented here are the first to demonstrate an efficient approach to achieve numerous $P$. bournei plantlets, which serves as the basis for artificial cultivation and resource conservation. Furthermore, the genetic transformation platform constructed in this study will facilitate assessment of gene function and molecular regulation.
\end{abstract}

Keywords: Agrobacterium; genetic transformation; Phoebe bournei; rapid multiplication; somatic embryogenesis

\section{Introduction}

Phoebe bournei (Hemsl.) Yang, a woody plant species endemic to China, was historically named "Golden Phoebe" wood in China (Chen et al., 2017). Timber of this woody plant was preferred by royalty and aristocrats for its light fragrance, gorgeous golden lustre, and non-perishable hard material (Chen et al., 2015). Since the Qin Dynasty in China, "Golden Phoebe" wood has been used in the construction of main pillars in audience halls and thrones for supreme rulers in numerous palaces. P. bournei is still famous for its excellent performance 
in artwork and new Chinese-style furniture (Jiang et al., 2008). In addition, this evergreen arbour species is widely used in modern landscaping, such as street trees and feature trees, given its graceful tree shape, straight trunk, and slender leaves (Jiang et al., 2009; Wu et al., 2015). Our recent research has revealed that $P$. bournei contains numerous monoterpenes and sesquiterpenes, such as $\alpha$-santalene, a main component of sandalwood oil, and $\alpha$-pinene, a medicinal compound with antibacterial and antitumour activity (unpublished data). These findings underscore the potential economic value of this tree. Therefore, artificial cultivation of this tree might satisfy the great market demand, thus underscoring its considerable potential value.

The habitat of $P$. bournei was once broadly situated in South China. However, natural resources of the species are being depleted because of excessive anthropogenic deforestation over a long period of time. Natural populations disappeared throughout localities recorded in historical data (Ge et al., 2012). Research on $P$. bournei started in the 1990s and mainly focused on its physiological and ecological characteristics (Wu, 2001; Jiang et al., 2009; Zheng et al., 2012; Liu et al., 2014; Hong et al., 2019), natural resource distribution (Ge et al., 2012; Chen et al., 2018), and artificial cultivation (Liu et al., 2011; Zhang et al., 2016; Cheng et al., 2018). Cultivation of this species is dependent on seedlings germinated from seeds, which increases the risk of variation and limits the marketization of the industry. In addition, a lack of clones and genetic transformation platforms has limited molecular genetics research on this species.

Somatic embryogenesis (SE) is based on cell totipotency and uniquely applicable to the plant kingdom. In this process, morphologically and developmentally normal embryos are generated from embryonic cells without undergoing fertilization (Zimmerman, 1993). The SE technical system was traditionally utilized to obtain a large number of clones in a short period of time, satisfying the demand for nursery stock production. Recently, given the need for gene functional studies in various plant species, SE technology has become the preferred method with which to construct genetic transformation systems and CRISPR/Cas9 systems, which have been successfully applied to many plant species (Leelavathi et al., 2004; Wang et al., 2017; Du et al., 2019).

Since the phenomenon of SE was first observed in carrot callus cells (Steward et al., 1958), SE has been reported in a large number of plant species. SE systems have been reported in over 200 plant species from Pinaceae (Salaj et al., 2003; Montalbán et al., 2013), Malvaceae (Wu et al., 2004), Magnoliaceae (Chen et al., 2003), Rutaceae (Singh et al., 2007), Burseraceae (Rugini et al., 1995), Vitaceae (Martinelli et al., 2001), and Poaceae (Vasil, 2005). Lauraceae is a large family including more than 2000 species. Many of these species have great economic value, such as avocado, laurel, and camphor tree. Recently, SE has been described in several species of this family. Mature zygotic embryos were cultured on modified Murashige and Skoog (MS) medium for SE in Ocotea catharinensis (Moura-Costa et al., 1993). For another species in this genus, Ocotea porosa, an immature embryonic axis was used as the explant, and woody plant medium (WPM) was used as the basal medium (Pelegrini et al., 2013). Torpedo-shaped embryos in MS medium achieved the highest induction frequency for SE in Cinnamomum pauciflorum (Kong et al., 2009). In Cinnamomum camphora, embryogenic cell lines were originally generated from immature zygotic embryos, and secondary SE could be maintained for more than four years via cyclic processes (Shi et al., 2010). Of note, both calluses and somatic embryos were induced from leaf bases after incubation at $4^{\circ} \mathrm{C}$ for two weeks in Laurus nobilis (Al-Gabbiesh et al., 2014). In Persea americana, SE was induced from zygotic embryos of various sizes and developmental stages by different researchers (Litz et al., 2002). However, SE research in the Phoebe genus has not been reported.

In this study, the $S E$ technical system of $P$. bournei was constructed successfully for the first time using immature embryos as original materials. Agrobacterium-mediated genetic transformation of the species via the SE technical system was performed using a green fluorescent protein as the marker gene. The results provided an approach with which to achieve numerous $P$. bournei plantlets for artificial cultivation and protection of natural resources. In addition, clones and genetic transformation using the SE system will further promote studies on molecular functions and mechanisms. 


\section{Materials and Methods}

\section{Explant materials and media preparation}

P. bournei bloomed in early May. Immature fruits were collected from Wuyuan County, Jiangxi Province, at 25th, June, 2018. Three wild individuals were selected based on growth conditions and fructification ability for fruit collection. Fruits from these three individuals constituted three half-sib families, which were referred to as hs-F1, hs-F2, and hs-F3. The fruits were divided into four developmental stages according to the length of fruit extending from the tepals. Embryo lengths in each stage were recorded.

MS medium (Murashige and Skoog, 1962) was applied as the basal medium for all cultures in this study. For all media, the $\mathrm{pH}$ was adjusted to $5.8-6.0$ before sterilisation at $121^{\circ} \mathrm{C}$ for $20 \mathrm{~min}$.

\section{Induction of primary somatic embryos}

After sterilization in $75 \%$ ethyl alcohol for $30 \mathrm{~s}$, immature fruits were opened using a scalpel on a clean bench. Endosperm occupied most of the space in the seed at the early developmental stage. The cotyledon-stage embryo was separated from the endosperm before inoculation into induction medium. Immature zygotic embryos were cultured at $25^{\circ} \mathrm{C}$ in the dark.

Four developmental stages of embryos in three half-sib families (hs-F1, hs-F2, and hs-F3) were analysed. At least 50 embryos in each treatment were inoculated into solid MS medium with $2.0 \mathrm{mg} / \mathrm{L} 2,4-\mathrm{D}, 1.0 \mathrm{mg} / \mathrm{L}$ 6-BA, $30.0 \mathrm{~g} / \mathrm{L}$ sucrose, $2.0 \mathrm{~g} / \mathrm{L}$ casein acid hydrolysate $(\mathrm{CH}), 1.0 \mathrm{~g} / \mathrm{L}$ activated carbon $(\mathrm{AC})$, and $8.0 \mathrm{~g} / \mathrm{L}$ agar. Data were recorded $60 \mathrm{~d}$ after inoculation.

Half-sib family hs-F2 was chosen for the experiment assessing plant growth regulators (PGRs) influence on primary embryo induction. Two PGRs were investigated in this experiment. The concentration gradient of 2,4-D was $0.5,1.0$, and $2.0 \mathrm{mg} / \mathrm{L}$, and that of $6-\mathrm{BA}$ was $0,0.5$, and $1.0 \mathrm{mg} / \mathrm{L}$. Basal culture medium was generated by adding $30.0 \mathrm{~g} / \mathrm{L}$ sucrose, $2.0 \mathrm{~g} / \mathrm{L} \mathrm{CH}, 1.0 \mathrm{~g} / \mathrm{L} \mathrm{AC}$, and $8.0 \mathrm{~g} / \mathrm{L}$ agar to the MS medium. Data were collected from at least 50 embryos in each treatment $60 \mathrm{~d}$ after inoculation.

\section{Embryonic callus induction}

Primary cotyledon-stage embryos from hs-F2 with a normally developed meristematic zone were chosen for the embryonic callus induction experiment. Basal culture medium was generated by adding $30.0 \mathrm{~g} / \mathrm{L}$ sucrose, $2.0 \mathrm{~g} / \mathrm{L} \mathrm{CH}, 1.0 \mathrm{~g} / \mathrm{L} \mathrm{AC}$, and $8.0 \mathrm{~g} / \mathrm{L}$ agar to the MS medium. Here, 0.5, 1.0, and $2.0 \mathrm{mg} / \mathrm{L} 2,4-\mathrm{D}$ and $0,0.5$, and $1.0 \mathrm{mg} / \mathrm{L} 6-\mathrm{BA}$ were used. Twenty embryos were examined in each treatment. The experiment was performed at $25^{\circ} \mathrm{C}$ in the dark. Primary embryos were transferred to fresh medium every $30 \mathrm{~d}$. The number of embryos generating embryonic callus $(\mathrm{n})$ was recorded $120 \mathrm{~d}$ after inoculation. The embryonic callus induction rate was calculated according to the following formula: Induction rate $=(\mathrm{n} / 20) \times 100 \%$.

\section{Embryonic callus proliferation}

Embryonic callus from hs-F2 that appeared light yellow in colour were selected for callus proliferation experiments. Embryonic callus ( $\mathrm{m} 1$, approximately $0.5 \mathrm{~g}$ ) was inoculated into one plate. Ten repetitions were performed in each treatment. The basal culture medium contained MS medium with $30.0 \mathrm{~g} / \mathrm{L}$ sucrose and 7.0 $\mathrm{g} / \mathrm{L}$ agar. In addition, 0 and $2.0 \mathrm{~g} / \mathrm{L} \mathrm{CH}$ were added. Here, $0.10,0.20$, and $1.00 \mathrm{mg} / \mathrm{L} 2,4-\mathrm{D}$ and $0.05,0.10$, and $0.50 \mathrm{mg} / \mathrm{L} 6-\mathrm{BA}$ were used. All plates were cultured at $25^{\circ} \mathrm{C}$ in the dark. Embryonic callus from each plate was collected and weighted $30 \mathrm{~d}$ after inoculation $(\mathrm{m} 2)$. The embryonic callus proliferation rate was calculated according to the following formula: Proliferation rate $=[(\mathrm{m} 2-\mathrm{m} 1) / \mathrm{m} 1] \times 100 \%$.

\section{Maturation and germination of somatic embryos}

Three genotypes (G1, G2, and G3) from family hs-F2 were selected to perform proliferation experiments, and embryonic callus in good condition was chosen for maturation and germination experiments. Embryonic callus (approximately $0.50 \mathrm{~g}$ ) was inoculated into one plate. Ten repetitions were performed for 
each genotype. Maturation medium was produced by adding $30.0 \mathrm{~g} / \mathrm{L}$ sucrose, $2.0 \mathrm{~g} / \mathrm{L} \mathrm{CH}$, and $8.0 \mathrm{~g} / \mathrm{L}$ agar to the MS medium. The experiment was performed at $25^{\circ} \mathrm{C}$ in the dark. Callus was transferred to fresh medium every $30 \mathrm{~d}$. The number of somatic embryos in each plate was recorded $90 \mathrm{~d}$ after the first inoculation.

Normal cotyledon-stage embryos with a milky white colour were chosen and transferred to a light environment for germination (the germination medium was similar the medium used for maturation). Five repetitions were performed for each genotype. Somatic embryos with developed shoots and roots were recorded as germinated somatic embryos. After $40 \mathrm{~d}$, the number of germinated somatic embryos in each genotype was recorded.

\section{Agrobacterium-mediated transformation of embryonic callus}

The transformation process in this study followed a standard protocol with some modifications (Walters et al., 1992). A single colony of Agrobacterium strain EHA 105 harbouring PBI121-GFP was cultured with shaking at $28^{\circ} \mathrm{C}$ for $12 \mathrm{~h}$ in liquid Luria broth (Bertani, 1951) with $50 \mathrm{mg} / \mathrm{L}$ spectinomycin. The bacterial solution with an $\mathrm{OD}_{600}=0.6-0.8$ was centrifuged at $3500 \mathrm{rpm}$ for $10 \mathrm{~min}$ and resuspended in liquid $1 / 2 \mathrm{MS}$ medium with acetosyringone (concentrations reported below) until the $\mathrm{OD}_{600}$ value of the resuspension was at least 0.3 . After recording the callus weight for each treatment $(\mathrm{m} 3)$, the callus was soaked in the bacterial solution for several minutes (durations are reported below) to complete the infection process. Callus was transferred to a plate with filter paper on the surface of co-culture medium (MS medium with $0.20 \mathrm{mg} / \mathrm{L}$, 2,4$\mathrm{D}, 0.10 \mathrm{mg} / \mathrm{L}$ 6-BA, $2.00 \mathrm{~g} / \mathrm{L} \mathrm{CH}, 30.0 \mathrm{~g} / \mathrm{L}$ sucrose, and $7.0 \mathrm{~g} / \mathrm{L}$ agar). After 2 days of co-cultivation, callus was transferred to proliferation medium (MS medium with $0.20 \mathrm{mg} / \mathrm{L}$ 2,4-d, $0.10 \mathrm{mg} / \mathrm{L}$ 6-BA, $2.0 \mathrm{~g} / \mathrm{L} \mathrm{CH}, 30.0$ $\mathrm{g} / \mathrm{L}$ sucrose, and $7.0 \mathrm{~g} / \mathrm{L}$ agar) with $300 \mathrm{mg} / \mathrm{L}$ cefotaxime for subsequent culture. After $60 \mathrm{~d}$ of proliferation, embryonic callus was observed under a fluorescent light source (LUYOR-3415RG). Callus with green fluorescence was separated from other callus, and the weight $(\mathrm{m} 4)$ was recorded. The transformation rate was calculated according to the following formula: Transformation rate $=\mathrm{m} 4 / \mathrm{m} 3 \times 100 \%$.

\section{Optimization of genetic transformation conditions}

Three conditions were studied in this study, namely, cefotaxime concentration, acetosyringone concentration, and infection duration.

Cefotaxime concentration: Embryonic callus was inoculated on medium containing 0, 200, 250, or $300 \mathrm{mg} / \mathrm{L}$ cefotaxime. Then, $0.5 \mathrm{~g}$ of callus was inoculated into each culture dish, and five replications were applied for each treatment. Photographs were taken $20 \mathrm{~d}$ after inoculation. The experiment was repeated three times.

Acetosyringone (AS) concentration: Bacterial solutions with 0, 100, 300, and $600 \mu \mathrm{M}$ AS were used for infection. After 3 mins of infection, the embryonic callus was removed to co-culture medium containing a consistent concentration of AS. Co-cultivation continued for 2 days, and the embryonic callus was subsequently transferred to proliferation medium with $300 \mathrm{mg} / \mathrm{L}$ cefotaxime. Five replications were applied for each treatment. The results were observed $20 \mathrm{~d}$ after infection. The experiment was repeated three times.

Infection duration: Embryonic callus was soaked into bacterial solution for 1, 3, 6, and 9 mins to complete the infection. The subsequent steps were the same as those reported above. Three replications were applied for each treatment. The results were observed $20 \mathrm{~d}$ after infection. The experiment was repeated three times.

\section{Statistical analysis}

In all experiments, the treatments were performed at least three times. The data were subjected to Duncan's multiple-range test at a 5\% probability using the SPSS software (IBM Inc., Stanford University, CA, USA). 


\section{Results}

\section{Influence of embryo developmental stage on primary embryo induction}

Embryo developmental stage was directly associated with the induction rate. However, the embryo is located inside the seed, and observations were difficult before the induction operation. The characteristics of the fruit developmental stage in $P$. bourneiserve as applicable markers for the embryo developmental stage. Fruit development was divided into four stages (Figure 1A). The embryo lengths $(\mathrm{mm})$ in each stage were $<1.0$, $\leq 1.0<2.0, \leq 2.0<3.0$, and $\geq 3.0$, respectively. In stage I, the fruit extended approximately $2 \mathrm{~mm}$ from the tepals (Figure 1A), and the embryo inside the fruit was less than $1 \mathrm{~mm}$. In this stage, the seed was filled with translucent endosperm, and a creamy white zygotic embryo appressed the end of endosperm far from carpopodium. In stage II, the portion of the fruit that extended from the tepals was 4-5 mm, and the zygotic embryo in the seed grew up to $1-2 \mathrm{~mm}$ in length. With embryo development, endosperm nutrients were gradually absorbed by the cotyledons, causing the zygotic embryo volume to increase (Figure 1B).
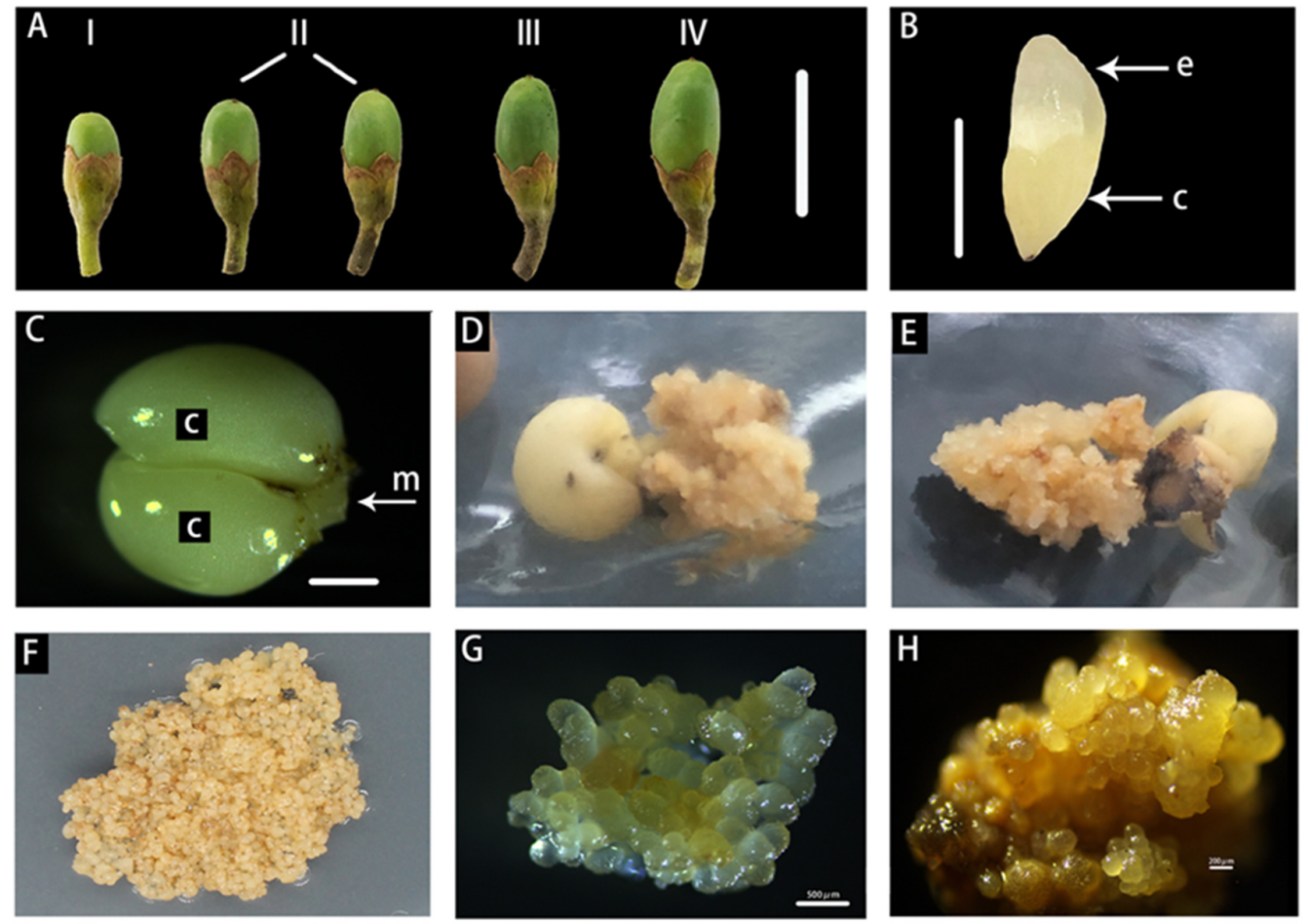

Figure 1. Induction and proliferation of embryonic calluses in P. bournei.

A: Different developmental stages of fruits, bar $=1 \mathrm{~cm} ; \mathbf{B}$ : Endosperm and cotyledon embryo in one seed (e: endosperm, c: cotyledon-stage embryo), bar $=1 \mathrm{~cm}$; C: Somatic embryo (c: cotyledon, m: meristematic region), bar=1 mm; D, E: Induction of embryonic callus from primary somatic embryos; F: Embryonic callus after proliferation; G: Embryonic callus from D, E under a stereoscope, bar $=500 \mu \mathrm{m} ; \mathbf{H}$ : Embryonic callus from F under a stereoscope, bar $=200 \mu \mathrm{m}$.

Primary somatic embryos (primary embryos) were directly generated from the meristematic region of zygotic embryos. Explants began to expand $10 \mathrm{~d}$ after inoculation. White globular embryos were noted in explant tissue $15 \mathrm{~d}$ after inoculation. Some of the globular embryos dropped onto the solid medium and continued to grow. Finally, cotyledon-stage embryos (Figure 1C) were obtained 90-120 d after inoculation. In this process, embryonic callus was also induced from some of the zygotic embryos. The induction rates of primary somatic embryos at different developmental stages were studied $60 \mathrm{~d}$ after inoculation (Table 1). Stage I embryos were too young and browned easily after inoculation in culture medium. On the other hand, the 
dedifferentiation ability of cells weakened as the embryo developed, leading to a decreased induction rate of primary somatic embryos and increased induction rate of deformed buds in stage III and beyond. Induction rates varied among the half-sib families, leading to a non-significant result $(P>0.05)$. The average induction rate in developmental stage II (the fruit extended $4-5 \mathrm{~mm}$ from the tepals, and the embryo was $1-2 \mathrm{~mm}$ in length) approached the peak level of $41.79 \%$.

Table 1. Induction rates of primary somatic embryo (\%)

\begin{tabular}{|c|c|c|c|c|}
\hline \multirow{2}{*}{ Family } & \multicolumn{4}{|c|}{ Developmental stage } \\
\cline { 2 - 5 } & $\mathrm{I}$ & II & III & IV \\
\hline hs-F1 & 20.00 & 38.89 & 20.45 & 11.90 \\
\hline hs-F2 & 30.43 & 57.89 & 37.21 & 11.48 \\
\hline hs-F3 & 16.36 & 28.57 & 23.64 & $15.69 \pm 5.66$ \\
\hline Average & $22.27 \pm 5.96$ & $41.79 \pm 12.15$ & $27.10 \pm 7.27$ & \\
\hline
\end{tabular}

\section{Influence of PGR combination on primary embryo and embryonic callus induction}

The combination of PGRs was important for primary embryo induction. Induction rates in treatments with only 2,4-D added were obviously reduced compared with those in the other treatments. The 2,4-D to 6BA application ratio was $2 / 1$. Higher concentrations of PGRs exhibited better performance in terms of primary embryo induction. In summary, the optimal combination of PGRs for primary embryo induction was $2.0 \mathrm{mg} / \mathrm{L}$ 2,4-D and $1.0 \mathrm{mg} / \mathrm{L} 6-\mathrm{BA}$, achieving the highest induction rate of 30.66\% (Table 2).

Table 2. Primary embryo and embryonic callus induction rates under different PGR combinations

\begin{tabular}{|c|c|c|c|c|}
\hline \multirow{2}{*}{$\begin{array}{c}\text { Treatment } \\
\text { No. }\end{array}$} & \multicolumn{2}{|c|}{ PGRs concentration $(\mathrm{mg} / \mathrm{L})$} & $\begin{array}{c}\text { primary embryo induction } \\
\text { rate }(\%)\end{array}$ & $\begin{array}{c}\text { embryonic callus } \\
\text { induction rate }(\%)\end{array}$ \\
\cline { 2 - 3 } & $2,4-\mathrm{D}$ & $6-\mathrm{BA}$ & $2.11 \pm 0.13 \mathrm{~g}$ & $11.67 \pm 4.71 \mathrm{bcd}$ \\
\hline 1 & 0.5 & 0.0 & $21.83 \pm 1.01 \mathrm{c}$ & $15.00 \pm 4.08 \mathrm{bc}$ \\
\hline 2 & 0.5 & 0.5 & $14.89 \pm 1.30 \mathrm{e}$ & $6.67 \pm 2.36 \mathrm{cde}$ \\
\hline 3 & 0.5 & 1.0 & $7.37 \pm 0.23 \mathrm{f}$ & $3.33 \pm 2.36 \mathrm{de}$ \\
\hline 4 & 1.0 & 0.0 & $25.15 \pm 1.39 \mathrm{~b}$ & $41.67 \pm 6.24 \mathrm{a}$ \\
\hline 5 & 1.0 & 0.5 & $19.27 \pm 0.79 \mathrm{~d}$ & $20.00 \pm 4.08 \mathrm{~b}$ \\
\hline 6 & 1.0 & 1.0 & $5.36 \pm 0.16 \mathrm{f}$ & $1.67 \pm 2.36 \mathrm{e}$ \\
\hline 7 & 2.0 & 0.0 & $17.75 \pm 1.47 \mathrm{~d}$ & $5.00 \pm 4.08 \mathrm{de}$ \\
\hline 8 & 2.0 & 0.5 & $30.66 \pm 1.93 \mathrm{a}$ & $11.67 \pm 4.71 \mathrm{bcd}$ \\
\hline 9 & 2.0 & 1.0 & & \\
\hline
\end{tabular}

Values followed by different letters are significantly different at $P<0.05$

Meristematic points of some primary embryos started inflating $15 \mathrm{~d}$ after inoculation, accompanied by the growth of light-yellow callus on them. Callus continued to grow and drop to the surface of solid medium $20 \mathrm{~d}$ after inoculation (Figure 1D, E). This kind of loosened callus had numerous spherical and subsphaeroidal granules that were 200-300 $\mu \mathrm{m}$ in length (Figure 1F). Another kind of callus typically existed after several subcultures and appeared as small gobbets (Figure $1 \mathrm{G}$ ) with a mass of spheroid structures on them that could be easily separated using tweezers (Figure $1 \mathrm{H}$ ).

Embryo callus induction required lower PGR concentrations compared with those required for primary embryo induction. Excessive PGRs increased the rate of browning and subsequently led to primary embryo death. The 2,4-D to 6-BA application ratio was consistent with that used for primary embryo induction, but the concentrations were reduced by half, i.e., to $1.0 \mathrm{mg} / \mathrm{L}$ and $0.5 \mathrm{mg} / \mathrm{L}$, respectively. The highest induction rate achieved was $41.67 \%$ (Table 2 ). 


\section{Influence of CH concentration and PGR combination on embryonic callus proliferation}

To maintain rapid proliferation, PGR concentrations must be sequentially reduced during proliferation. The optimal PGR combination for proliferation was $0.2 \mathrm{mg} / \mathrm{L}$ 2,4-D and $0.1 \mathrm{mg} / \mathrm{L}$ 6-BA (Table 3). The addition of casein hydrolysate $(\mathrm{CH})$ to the medium as a nutriment was necessary for callus proliferation in $P$. bournei. The absence of $\mathrm{CH}$ led to browning, callus weight reduction, and even callus death (Table 3 ). The highest embryonic callus proliferation rate of 3.84 was noted in treatment 5 (MS with $0.2 \mathrm{mg} / \mathrm{L} 2,4-\mathrm{D}, 0.1$ $\mathrm{mg} / \mathrm{L} \mathrm{6-BA}$ and $2 \mathrm{~g} / \mathrm{L} \mathrm{CH}$ ).

Table 3. Proliferation rates of embryonic callus under different culture conditions

\begin{tabular}{|c|c|c|c|c|}
\hline \multirow{2}{*}{ Treatment No. } & \multirow{2}{*}{$\mathrm{CH}(\mathrm{g} / \mathrm{L})$} & \multicolumn{2}{|c|}{ PGRs concentration $(\mathrm{mg} / \mathrm{L})$} & \multirow{2}{*}{ Proliferation rate } \\
\cline { 3 - 4 } & & $2,4-\mathrm{D}$ & $6-\mathrm{BA}$ & \\
\hline 1 & 0.00 & 0.10 & 0.05 & $-0.20 \pm 0.14 \mathrm{e}$ \\
\hline 2 & 0.00 & 0.20 & 0.10 & $0.54 \pm 0.19 \mathrm{~d}$ \\
\hline 3 & 0.00 & 1.00 & 0.50 & $0.23 \pm 0.06 \mathrm{~d}$ \\
\hline 4 & 2.00 & 0.10 & 0.05 & $2.04 \pm 0.48 \mathrm{~b}$ \\
\hline 5 & 2.00 & 0.20 & 0.10 & $3.84 \pm 0.69 \mathrm{a}$ \\
\hline 6 & 2.00 & 1.00 & 0.50 & $1.61 \pm 0.39 \mathrm{c}$ \\
\hline
\end{tabular}

Values followed by different letters are significantly different at $P<0.05$

\section{Maturation and germination of somatic embryos}

The maturation process of $P$. bournei in MS medium without PGRs involved four stages, including the globular, heart-shaped, torpedo-shaped and cotyledon stages (Figure 2A, B, C, and D), which lasted approximately $60 \mathrm{~d}$. Globular embryos (Figure 2A) were observed during callus proliferation. When the embryonic callus was transferred to PGR-free medium, globular embryos entered into the maturation process. In the heart-shaped stage, continuous division of cells located on both sides of the meristematic region formed two bulges, displaying the characteristic heart-shaped embryo (Figure 2B). In the torpedo-shaped stage, the meristematic region was elongated to separate the shoot apical meristem and root apical meristem (Figure 2C). Upon entry to the cotyledon stage, embryo volume increased, and two bulges located on both sides of the shoot apical meristem sequentially developed to form two cotyledons (Figure 2D). After $60 \mathrm{~d}$ with two subcultures, the colour of the cotyledon embryo changed from light yellow to milky white (Figure 2E). Embryos became green $60 \mathrm{~d}$ after exposing them to the light environment, and germination started 25-30 d later (Figure 2F). Figure 2G-I showed roots of seedlings in different developmental stages. The maturity capacities of the somatic embryos were dependent on genotype. However, the germination rates of somatic embryos with different genotypes did not significantly differ $(P>0.05)$. The maximal maturity coefficient and germination rate were 53.44/g and 39\%, respectively (Table 4).

Table 4. Maturation and germination of somatic embryos with different genotypes

\begin{tabular}{|c|c|c|}
\hline Genotype & Mature coefficient $(/ \mathrm{g})$ & Germination rate (\%) \\
\hline G1 & $32.39 \pm 6.71 \mathrm{c}$ & $31.00 \pm 8.60$ \\
\hline G2 & $16.03 \pm 4.55 \mathrm{~b}$ & $32.50 \pm 12.75$ \\
\hline G3 & $53.44 \pm 10.17 \mathrm{a}$ & $39.00 \pm 9.70$ \\
\hline
\end{tabular}

Values followed by different letters are significantly different at $P<0.05$ 

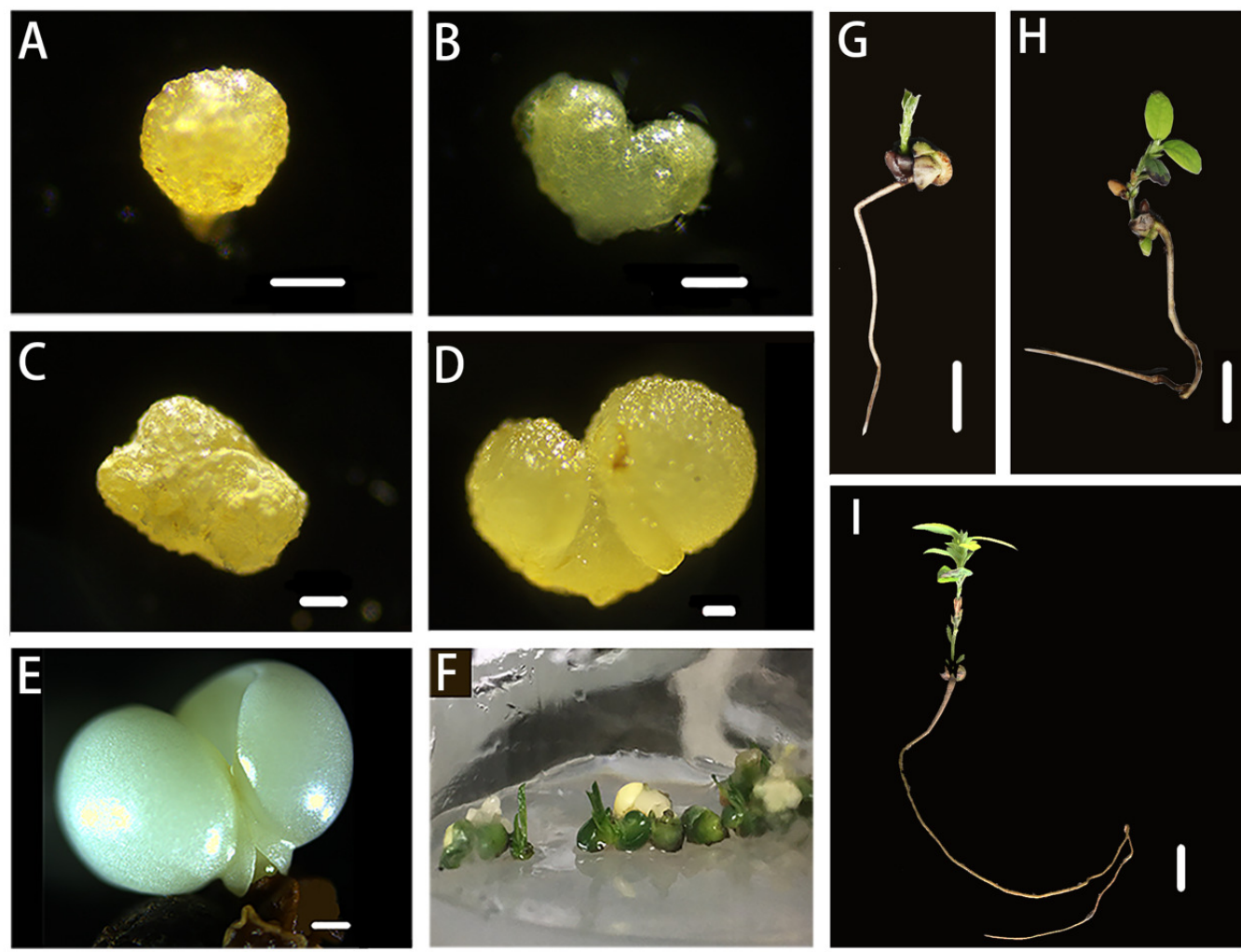

Figure 2. Somatic embryo maturation and germination

A: Globular embryo, bar $=200 \mu \mathrm{m}$; B: Heart-shaped embryo, bar=200 $\mu \mathrm{m}$; C: Torpedo-shaped embryo, bar $=200 \mu \mathrm{m}$; D: Initial cotyledon-stage embryo, bar=200 $\mu \mathrm{m}$; E: Later cotyledon-stage embryo, bar=500 $\mu \mathrm{m}$; F: Germination of somatic embryos under light; G: Germinated somatic embryo with a normally developed shoot and root; H: Seedling with the first round of leaves unfolded; I: Normally developed seedling from a somatic embryo

Optimal concentrations of cefotaxime and acetosyringone (AS) for Agrobacterium-mediated transformation

Cefotaxime was used for Agrobacterium growth inhibition after co-cultivation. According to Figure 3A$\mathrm{D}$, callus grew normally in the presence of cefotaxime at all concentrations. Here, $300 \mathrm{mg} / \mathrm{L}$ cefotaxime was used given its bacteriostatic effect.

The use of AS as a surfactant in this experiment was required for successful infection (Table 5). However, high concentrations of AS resulted in growth cessation and browning of embryonic calluses (Figure 3E-H). In conclusion, the optimal AS concentration was $100 \mu \mathrm{mol} / \mathrm{L}$, achieving a transformation rate of $10.70 \%$. Obvious green fluorescence signals were observed under a fluorescent light source after transformation (Figure 4). Genomic DNA extracted from tissue with green fluorescence signal and callus without transformation were detected for $g f p$ gene. PCR analysis indicated the presence of $g f p$ gene (amplicon at about $440 \mathrm{bp}$ ) in tissue with green fluorescence signal (Figure 5). 

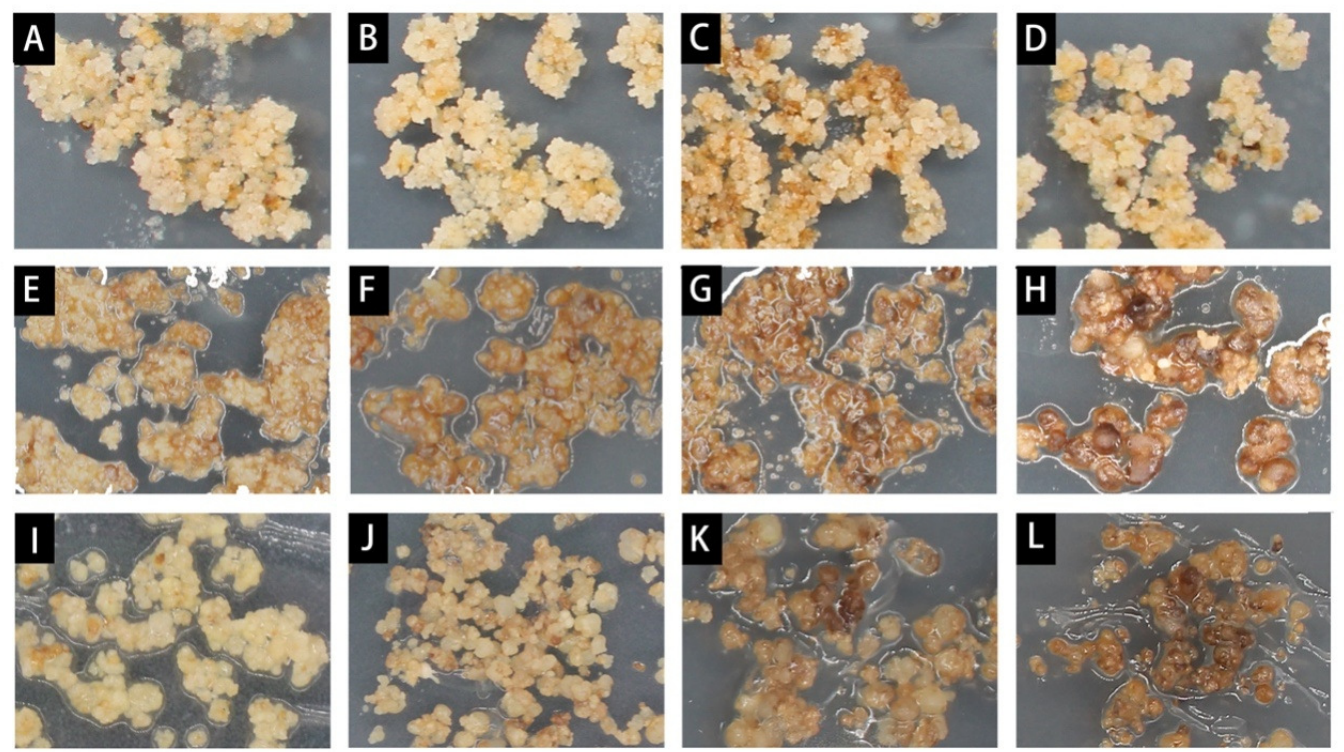

Figure 3. Optimization of genetic transformation conditions

A-D: Concentrations of cefotaxime in this line from left to right were $0,200,250$, and $300 \mathrm{mg} / \mathrm{L}$, respectively; E-H: Concentrations of acetosyringone in this line from left to right were 0, 100, 300, and $600 \mu \mathrm{M}$, respectively; I-L: Infection durations in this line from left to right were 1, 3, 6, and 9 mins, respectively
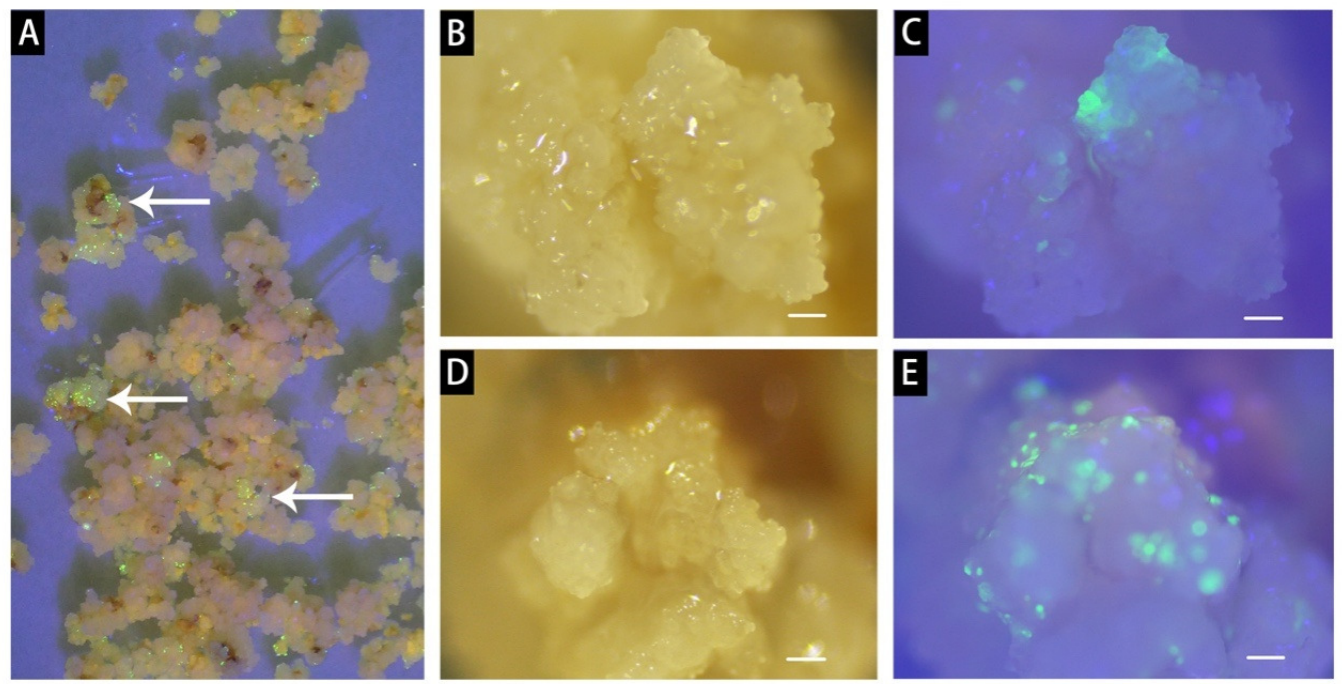

Figure 4. Agrobacterium-mediated transformation of embryonic callus in P. bournei

A: Transformed callus photographed under a fluorescent light source using an SLR camera (arrows show gathered transformed callus with green fluorescence); B, D: Embryonic callus under natural light assessed using a stereoscope, bar $=200 \mu \mathrm{m} ; \mathbf{C}, \mathbf{E}$ : Corresponding callus under a fluorescent light source assessed using a stereoscope, bar $=200 \mu \mathrm{m}$ 


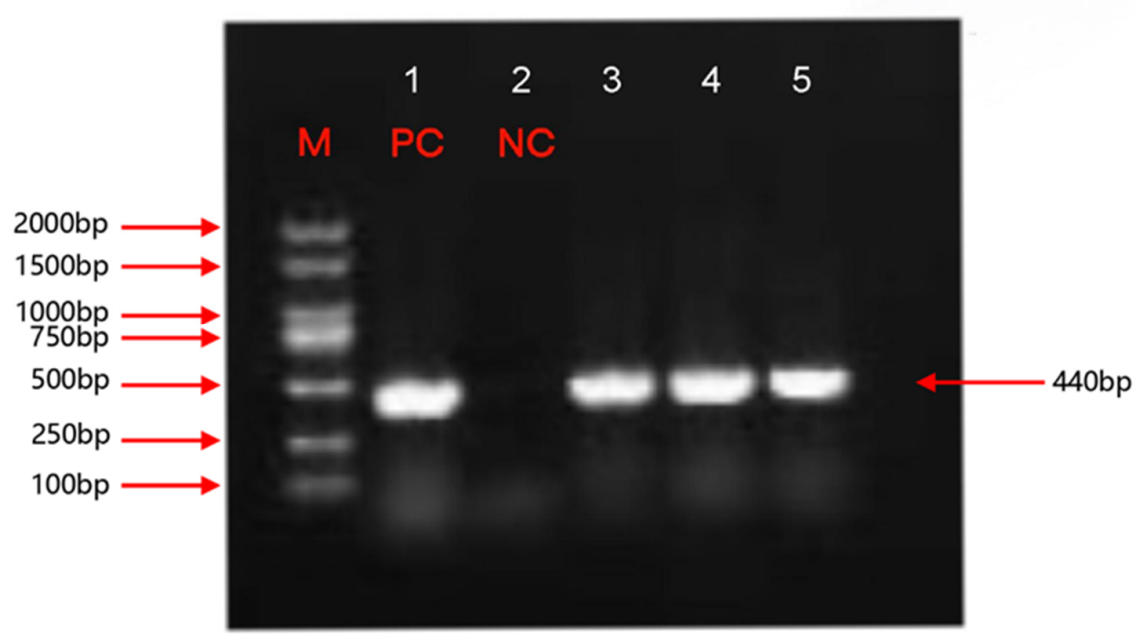

Figure 5. PCR analysis of $g f p$ gene in transformed callus

M, BM2000 DNA marker; PC, positive control, Agrobacterium with $g f p$ gene; NC, negative control, genomic DNA from non-transformed callus; lanes 3-5, genomic DNA from transformed callus

Table 5. Transformation rates under different concentrations of AS and infection duration (\%)

\begin{tabular}{|c|c|c|c|c|c|c|c|c|}
\hline \multirow{2}{*}{ Genotype } & \multicolumn{3}{|c|}{ Concentration of AS $(\mu \mathrm{mol} / \mathrm{L})$} & \multicolumn{3}{c|}{ Infection duration (min) } \\
\cline { 2 - 9 } & 0 & 100 & 300 & 600 & 1 & 3 & 6 & 9 \\
\hline G1 & 0.00 & $8.29 \pm 2.37$ & NA & NA & $9.34 \pm 0.70$ & $7.96 \pm 1.72$ & NA & NA \\
\hline G2 & 0.00 & $5.29 \pm 1.55$ & NA & NA & $10.16 \pm 1.71$ & $11.12 \pm 2.71$ & NA & NA \\
\hline G3 & 0.00 & $10.70 \pm 3.41$ & NA & NA & $11.09 \pm 2.38$ & $11.24 \pm 1.72$ & NA & NA \\
\hline
\end{tabular}

\section{Optimal infection duration of Agrobacterium}

The growth of embryonic callus after infection was influenced by Agrobacterium infection duration. In this experiment, embryonic callus growth was strongly inhibited after 6- and 9-min infection durations (Figure $3 \mathrm{~K}, \mathrm{~L})$. After a 3-min infection, embryonic callus browning was reduced, and growth conditions improved (Figure 3J). Embryonic callus grew normally under a 1-min infection duration (Figure 3I). Minimal differences in transformation rates were noted for infection durations of 1 (11.09\%) and 3 (11.24\%) minutes (Table 5). Moreover, embryonic callus was soaked in bacterial solution for $1 \mathrm{~min}$ to complete the infection. The highest transformation rate was $11.09 \%$.

In summary, the SE technical system of $P$. bournei could be divided into five stages, namely, primary embryo induction, embryonic callus induction, embryonic callus proliferation, somatic embryo maturation, and somatic embryo germination. The genetic transformation of embryonic callus involved infection, coculture, and proliferation culture. The culture conditions of these stages are listed in Table 6.

Table 6. Culture conditions of different experimental stages 
Xu W et al. (2020). Not Bot Horti Agrobo 48(2):572-587

\begin{tabular}{|c|c|c|c|c|c|c|c|c|c|c|c|c|}
\hline \multirow{3}{*}{\multicolumn{2}{|c|}{ Experimental stages }} & \multicolumn{9}{|c|}{ Culture medium } & \multirow{3}{*}{$\begin{array}{l}\text { Light } \\
\text { cond. }\end{array}$} & \multirow{3}{*}{$\begin{array}{c}\text { Culture } \\
\text { time } \\
\text { (d) }\end{array}$} \\
\hline & & \multirow[b]{2}{*}{$\begin{array}{c}\text { Basal } \\
\text { medium }\end{array}$} & \multicolumn{2}{|c|}{ PGRs (mg/L) } & \multicolumn{6}{|c|}{ Other components } & & \\
\hline & & & 2,4-D & $6-\mathrm{BA}$ & $\begin{array}{c}\text { Sucrose } \\
(\mathrm{g} / \mathrm{L})\end{array}$ & $\begin{array}{l}\mathrm{CH} \\
(\mathrm{g} / \mathrm{L})\end{array}$ & $\begin{array}{c}\mathrm{AC} \\
(\mathrm{g} / \mathrm{L}) \\
\end{array}$ & $\begin{array}{l}\text { Agar } \\
(g / L)\end{array}$ & $\begin{array}{c}\text { Cefotaxime } \\
(\mathrm{mg} / \mathrm{L})\end{array}$ & $\begin{array}{c}\text { AS } \\
(\mu \mathrm{M})\end{array}$ & & \\
\hline \multirow{5}{*}{$\begin{array}{c}\text { Somatic } \\
\text { embryogesis }\end{array}$} & $\begin{array}{c}\text { Primary embryo } \\
\text { induction }\end{array}$ & MS & 2 & 1 & 30 & 2 & 1 & 8 & - & - & Dark & 60 \\
\hline & Callus induction & MS & 1 & 0.5 & 30 & 2 & 1 & 8 & - & - & Dark & 120 \\
\hline & $\begin{array}{c}\text { Callus } \\
\text { proliferation }\end{array}$ & MS & 0.2 & 0.1 & 30 & 2 & - & 7 & - & - & Dark & 30 \\
\hline & $\begin{array}{c}\text { Mature of } \\
\text { somatic embryo }\end{array}$ & MS & - & - & 30 & 2 & - & 8 & - & - & Dark & 90 \\
\hline & $\begin{array}{l}\text { Germination of } \\
\text { somatic embryo }\end{array}$ & MS & - & - & 30 & 2 & - & 8 & - & - & Light & 40 \\
\hline \multirow{2}{*}{$\begin{array}{c}\text { Genetic } \\
\text { transformation }\end{array}$} & Co-culture & MS & 0.2 & 0.1 & 30 & 2 & - & 7 & - & 300 & Dark & 2 \\
\hline & $\begin{array}{c}\text { Proliferation } \\
\text { culture }\end{array}$ & MS & 0.2 & 0.1 & 30 & 2 & - & 7 & 300 & - & Dark & 60 \\
\hline
\end{tabular}

\section{Discussion}

With the development of the Chinese economy, an increasing number of people have a high quality of life. The traditional precious woody plant $P$. bourne $i$ is one of the most suitable candidates to meet the resulting demands. Therefore, $P$. bournei is a woody plant species worthy of further study given its significant ecological and economic value. Artificial cultivation of the species relies on seeds and is strongly impacted by limited natural resources and biennial bearing of fruit (Zhang et al., 2016). In addition, the deep dormancy of the seeds protracts germination and extends the breeding cycle (Zhang, 2013). Cutting and tissue culture represent potential solutions discussed by growers (Shen, 2013). However, cutting is rarely applied to $P$. bournei trees (the rooting rate was only $11.1 \%$ ) (Shen, 2013). Tissue culture was performed using different types of explants, but regenerated plantlets were not obtained. The SE system developed in our study provides a feasible approach for vegetative propagation, which could satisfy the needs of artificial cultivation.

The developmental stage of immature embryos is important for primary somatic embryo induction. Generally, a lower level of embryonic differentiation was associated with a higher induction rate of somatic tissue, indicating that an earlier developmental stage of immature embryos was appropriate for somatic embryo induction (Merkle et al., 1998). However, results in Liriodendron hybrids were different. Embryos at the developmental stages of globular embryo to initial cotyledon embryo were the optimal explants (Chen, 2003). In this study, fruit and embryo development was divided into four stages. The results showed that developmental stage II had the highest primary embryo induction rate, which was consistent with that reported in Liriodendron hybrids. These differences are attributed to increased young tissue browning compared with that in the tissues at later developmental stages, which led to tissue death. Therefore, the optimal developmental stage for induction of immature embryos was related to a high somatic tissue induction rate and low browning rate in $P$. bournei.

Various concentrations and combinations of PGRs have been used in SE studies of various plant species. Most plant species require PGRs, especially auxins and cytokinins, to complete the induction of embryonic tissue from explants, likely due to the key roles of the two PGRs in cell dedifferentiation and division (Li et al., 2019; Zhang et al., 2018; Liu et al., 2014). In the maturation stage, abscisic acid is necessary for conifer growth (Kim and Moon, 2007). By contrast, PGR-free medium is used for angiosperms (Merkle et al., 1998; Khan et al., 2010). PGR modulation is essential for SE in P. bournei. High concentrations of 2,4-D and 6-BA promoted primary embryo induction, whereas embryonic callus induction from primary embryos required half the concentrations of 2,4-D and 6-BA. However, embryonic callus proliferation was maintained by low concentrations of PGRs (excessive 2,4-D and 6-BA resulted in callus browning). Somatic embryos of $P$. bournei matured spontaneously in PGR-free MS medium, but this process required a long time. Thus, factors promoting maturation should be identified in further research. 
In addition to PGRs, several other factors influenced the SE. The nitrogen source plays an essential role in SE. Nitrate and ammonium significantly improve the induction of SE in Cucurbita pepo (Penciket al., 2015), Coffea arabica (Fuentes-Cerda et al., 2001), and Medicago sativa (Walker and Sato, 1981). On the other hand, as a supplier of organic nitrogen, $\mathrm{CH}$ is necessary for the induction of SE in Phoenix dactylifera (Al-Khayri, 2011), some grapevine cultivars (Prado et al., 2010), and Picea glauca (Barrett et al., 1997). In this study, the absence of $\mathrm{CH}$ inhibited embryonic callus proliferation, leading to browning. The embryonic callus in this study could grow normally in medium with $2 \mathrm{~g} / \mathrm{L} \mathrm{CH}$. This fact suggested that organic nitrogen is a crucial factor for embryonic callus proliferation in $P$. bournei.

In this one-year study, it took approximately 8 months to obtain seedlings from embryonic callus, and embryonic callus proliferated for 4 cycles ( 4 months). Therefore, the theoretical proliferation efficiency was $3.84^{4} \times 53.44 / \mathrm{g} \times 39 \%=4531.59$ seedlings/g/year, indicating that 4531.59 seedlings could be obtained from one gram of embryonic callus in one year. This result suggested the great potential of SE for vegetative propagation in P. bournei. However, low germination levels of somatic embryos were noted compared with those in other species. The probable explanations were as follows. First, the low germination rate may be due to the growth rhythm of this species itself. The germination experiments were performed in October and November. Meanwhile, other $P$. bournei materials, such as callus also exhibited poor growth. Second, statistical analysis was performed before the germination of some somatic embryos. Embryo germination in P. bournei may require more time than previously suspected.

The optimal concentration of acetosyringone and infection duration for Agrobacterium-mediated transformation vary according to plant species and tissue type (Sidorov and Duncan, 2009; Karthikeyan et al., 2011; Mehrotra and Sanyal, 2011). Transformation efficiency in the same species using the same tissue was associated with these two factors (Karthikeyan et al., 2011). Transformation efficiency was improved by increasing the acetosyringone concentration, while the infection duration had no effect in this study. However, these two factors were related to embryonic callus browning. Embryonic callus growth was completely inhibited when adding greater than $300 \mu \mathrm{mol} / \mathrm{L}$ acetosyringone or when using an infection duration greater than $6 \mathrm{~min}$. Alleviating embryonic callus browning during genetic transformation was critical to improving the transformation efficiency in P. bournei.

SE, which has been applied in some conifers, such as loblolly pine (Pullman et al., 2003) and radiate pine (Montalbánet al., 2010), has the potential to meet the demands of the forest product industry. In P. bournei, 4531.59 seedlings could be obtained per gram of embryonic callus in one year, which could completely satisfy the need for artificial cultivation. Agrobacterium-mediated transformation for SE was achieved in many plant species. In Gentianautriculosa, transformed plants that contained DNA sequences coding for the $\beta$ glucuronidase enzyme exhibited at least 2.5 -fold increased decussation compared with that of non-transformed plants (Vinterhalteret al., 2019). Secondary metabolites in $P$. bournei, such as $\alpha$-santalene and $\alpha$-pinene, are valuable to the cosmetics and pharmaceutical industries. Agrobacterium-mediated transformation provided an efficient approach to create cell lines with high yields of these compounds, and SE made rapid proliferation of these cell lines possible. The results in this study break the bottleneck of theoretical research and practical production in $P$. bournei, thus protecting the precious woody plant in a sustainable manner.

\section{Conclusions}

In this study, an SE technical system for $P$. bournei was successfully constructed for the first time. Agrobacterium-mediated genetic transformation of the species using the SE technical system was achieved. The results provided an approach to produce numerous $P$. bournei plantlets for artificial cultivation and natural 
resource protection. In addition, clones and the genetic transformation system based on the SE system will facilitate further studies on molecular function and possible mechanisms.

\section{Acknowledgements}

We thank Professor Jinfeng Zhang, Doctor Jian Zhao, and Shuaizheng Qi (Beijing Forestry University, Beijing, China) for guidance regarding somatic embryo induction. The Agrobacterium strain EHA 105 harbouring PBI121-GFP was kindly provided by Doctor Yi An (Zhejiang A\&F University, Hangzhou, China). This work was supported by the Zhejiang Science and Technology Major Program on Agricultural New Variety Breeding (Grant no. 2016C02056-2), the Forestry Science and Technology Project of Zhejiang (Grant no. 2017SY19), and a grant from the State Key Laboratory of Subtropical Silviculture (Grant no. KF2017-09). The first author thanks Mr. Zhan Xiao for his warmth, courage and tenacity.

\section{Conflict of Interests}

The authors declare that there are no conflicts of interest related to this article.

\section{References}

Al-Gabbiesh AH, Ghabeish, IH, Kleinwächter M, Selmar D (2014). Plant regeneration through somatic embryogenesis from calli derived from leaf bases of Laurus nobilis L. (Lauraceae). Plant Tissue Culture and Biotechnology 24(2):213-221.

Al-Khayri JM (2011). Influence of yeast extract and casein hydrolysate on callus multiplication and somatic embryogenesis of date palm (Phoenix dactylifera L.). Scientia Horticulturae 130:531-535.

Barrett JD, Park YS, Bonga JM (1997). The effectiveness of various nitrogen sources in white spruce [Picea glauca (Moench) Voss] somatic embryogenesis. Plant Cell Reports 16:411-415.

Bertani G (1951). Studies on lysogenesis. I. The mode of phage liberation by Lysogenic Escherichia coli. Journal of Bacteriology 62:293-300.

Chen GD, Huang TL, Lei FJ, Liu XL, Chen Y, Liang RL (2017). The wood anatomical structural characteristics for Phoebe bournei. Guangxi Forestry Science 46:375-379.

Chen JH, Shi JS, Zhuge Q, Huang MR (2003). Studies on the somatic embryogenesis of Liriodendron hybrids (L. chinese $\times$ L. tulipifera). Scientia Silvae Sinicae 39:49-53.

Chen RY, Guo JZ, Zhu TX (2015). Structure characteristics of Machilus microcarpa and Phoebe bournei. Journal of Forest and Environment 35:358-363.

Chen YZ, Miu SY, HuangJL, Chen WL, Dai WT, Wang HL, Zhang GL (2018). Study on the population's characteristics of rare and endangered plants in Longwen-Huangtian Natural Reserve of Pingyuan, Guangdong Province. Forestry and Environmental Science 34:59-65.

Cheng LL, Yin GT, Huang YQ, Yang JC, Zou WT, Yu N, ... Zheng YP (2018). Early growth evaluation and selection of germplasm resources of Phoebe bournei provenances families. Molecular Plant Breeding 16:5108-5116.

Du DX, Jin RC, Guo JJ, Zhang FD (2019). Infection of embryonic callus with Agrobacterium enables high-speed transformation of Maize. International Journal of Molecular Sciences 20:1-15.

Fuentes-Cerda CFJ, Monforte-González M, Méndez-Zeel M, Rojas-Herrera R, Loyola-Vargas VM (2001). Modification of the embryogenic response of Coffea arabica by nitrogen source. Biotechnology Letters 23:1341-1343.

Ge YJ, Wang JF, Fang W, Ye RH (2012). Distribution pattern of Phoebe bournei (Hemsl.) Yang and the characteristics of climate. Acta Agriculturae Universitatis Jiangxiensis 34:749-753.

Hong YC, Wang QQ, Huang JT, Meng QY, Qiu MJ, Wang YS, Le FQ (2019). Soil fertility and water conservation capacity of Phoebe bournei plantations. Journal of Northeast Forestry University 47:69-73. 
Jiang XM, Xiao FM, Gong B, Ye JS (2008). Study on physical and mechanical properties of Phoebe bournei wood from plantation and natural forest. Forest Research 21:862-866.

Jiang XM, Xiao FM, Ye JS, Gong B (2009). A study on the growth characteristics of Phoebe bourneiin natural forest and plantation stands. Acta Agriculturae Universitatis Jiangxiensis 31:1049-1054.

Karthikeyan A, Pandian SK, Ramesh M (2011). Agrobacterium-mediated transformation of leaf base derived callus tissues of popular indica rice (Oryza sativa L. sub sp. indica cv. ADT 43). Plant Science 181:258-268.

Khan T, Reddy VS, Leelavathi S (2010). High-frequency regeneration via somatic embryogenesis of an elite recalcitrant cotton genotype (Gossypium hirsutum L.) and efficient Agrobacterium-mediated transformation. Plant Cell, Tissue and Organ Culture 101:323-330.

Kim YW, Moon HK (2007). Enhancement of somatic embryogenesis and plant regeneration in Japanese larch (Larixleptolepis). Plant Cell, Tissue and Organ Culture 88:241-245.

Kong L, Dai D, Shang M, Li K, Zhang CX (2009). Thidiazuron-induced somatic embryos, their multiplication, maturation, and conversion in Cinnamomum pauciflorum Nees (Lauraceae). New Forests 38:131-142.

Leelavathi S, Sunnichan VG, Kumria R, Vijaykanth GP, Bhatnagar RK, Reddy VS (2004). A simple and rapid Agrobacterium-mediated transformation protocol for cotton (Gossypium hirsutum L.): embryonic callus as a source to generate large numbers of transgenic plants. Plant Cell Reports 22:465-470.

Li J, Wang M, Li Y, Zhang Q, Lindsey K, Daniell H, Jin S, Zhang X (2018). Multi-omics analyses reveal epigenomics basis for cotton somatic embryogenesis through successive regeneration acclimation process. Plant Biotechnology Journal

Li J, Wang M, Li Y, Zhang Q, Lindsey K, Daniell H, ... Zhang X (2019). Multi-omics analyses reveal epigenomics basis for cotton somatic embryogenesis through successive regeneration acclimation process. Plant Biotechnology Journal 17(2):435-450. https://doi.org/10.1111/pbi.12988

Litz RE, Litz W (2002). Somatic embryogenesis of avocado (Persea americana) and its application for plant improvement. Acta Horticulturae 575:133-138.

Liu B, Chen CJ, Lin DD, Lin SZ (2014). Analyses of photosynthetic pigment content and chlorophyll fluorescence parameter in leaves of 21 provenances of Phoebe bournei. Acta Agriculturae Universitatis Jiangxiensis 36:115-121.

Liu J, Jiang JM, Chen YT, Dong RX, Jiang RB, Kong C (2011). Cultural techniques of container seedlings with light medium and family selection for Phoebe bournei. Journal of Northwest Forestry University 26:70-73.

Liu X, Dinh TT, Li D, Shi B, Li Y, Cao X, Guo L, Pan Y, Jiao Y, Chen X (2014). AUXIN RESPONSE FACTOR 3 integrates the functions of $A G A M O U S$ and APETALA2 in floral meristem determinacy. The Plant Journal 80:629-641.

Martinelli L, Candioli E, Costa D, Poletti V, Rascio N (2001). Morphogenic competence of Vitis ruperis S. secondary somatic embryos with a long culture history. Plant Cell Reports 20:279-284.

Mehrotra M, Sanyal I (2011). High-efficiency Agrobacterium-mediated transformation of chickpea (Cicer arietinum L.) and regeneration of insect-resistant transgenic plants. Plant Cell Reports 30:1603-1616.

Merkle SA, Neu KA, Battle PJ, Bailey RL (1998). Somatic embryogenesis and plantlet regeneration from immature and mature tissues of sweetgum (Liquidambar styraciflua). Plant Science 132:169-178.

Montalbán IA, Diego ND, Moncaleán (2010). Bottlenecks in Pinus radiata somatic embryogenesis: improving maturation and germination. Trees 24:1061-1071.

Montalbán IA, Setién-Olarra A, Hargreaves CL, Moncaleán P (2013). Somatic embryogenesis in Pinus halepensis Mill.: an important ecological species from the Mediterranean forest. Trees 27:1339-1351.

Moura-Costa PH, Viana AM, Mantell SH (1993). In vitro plantlet regeneration of Ocotea catharinensis, an endangered Brazilian hardwood forest tree. Plant Cell, Tissue and Organ Culture 35:279-286.

Murashige T, Skoog F (1962). A revised medium for rapid growth and bioassays with tobacco tissue culture. Physiologia Plantarum 15:473-497.

Ou JD (2015). Combination selection of excellent families and plus trees of Phoebe bournei. Journal of Southwest Forestry University 35:33-37.

Pelegrini LL, RibasLLF, Amano E, Quoirin M (2013). Somatic embryogenesis and morphoanatomy of Ocotea porosa somatic embryos. Ciencia Florestal 23:595-605. 
Pencik A, Tureková V, Paulisiç S, Rolcik J, Strnad M, Mihaljevic S (2015). Ammonium regulates embryogenic potential in Cucurbita pepo through $\mathrm{pH}$-mediated changes in endogenous auxin and abscisic acid. Plant Cell, Tissue and Organ Culture 122:89-100.

Prado MJ, Grueiro MP, González MV, Testillano PS, Domínguez C, López M, Rey M (2010). Efficient plant regeneration through somatic embryogenesis from anthers and ovaries of six autochthonous grapevine cultivars from Galicia (Spain). Scientia Horticulturae 125:342-352.

Pullman GS, Johnson S, Peter G, Cairney J, Xu N (2003). Improving loblolly pine somatic embryo maturation: comparison of somatic and zygotic embryo morphology, germination, and gene expression. Plant Cell Reports 21:747-758.

Rugini E, Caricato G (1995). Somatic embryogenesis and plant recovery from mature tissues of olive cultivars (Olea europaea L.) "Canino" and “Moraiolo". Plant Cell Reports 14:257-260.

Salaj T, Salaj J (2003). Somatic embryo formation on mature Abies alba $\times$ Abies cephalonica zygotic embryo explants. Biologia Plantarum 47:7-11.

Shen Z (2013). Asexual propagation techniques of Pohebe bournei. Central South University of Forestry \& Technology, Changsha.

Shi X, Dai X, Liu G, Zhang J, Ning G, Bao M (2010). Cyclic secondary somatic embryogenesis and efficient plant regeneration in camphor tree (Cinnamomum camphora L.). In Vitro Cellular \& Developmental Biology - Plant 46:117-125.

Sidorov V, Duncan D (2009). Agrobacterium-mediated maize transformation: immature embryos versus callus. Agrobacterium-mediated maize transformation. Chapter 4:47-58.

Singh B, Sharma S, Rani G, Virk GS, Zaidi AA, Nagpal A (2007). In vitro response of encapsulated and nonencapsulated somatic embryos of Kinnow mandarin (Citrus nobilis Lour $\times$ C. deliciosa Tenora). Plant Biotechnology Reports 1:101-107.

Steward FC, Mapes MO, Smith J (1958). Growth and organized development of cultured cells. I. Growth and division of freely suspended cells. American Journal of Botany 45:693-703.

Vasil IK (2005). The story of transgenic cereals: the challenge, the debate, and the solution - a historical perspective. In Vitro Cellular \& Developmental Biology-Plant 41:577-583

Vinterhalter B, Savić J, Zdravković-Korać S, Banjac N, Vinterhalter D, Krstić-Milošević D (2019). Agrobacterium rhizogenes-mediated transformation of Gentiana utriculosa L. and xanthones decussatin-1-O-primeveroside and decussatin accumulation in hairy roots and somatic embryo-derived transgenic plants. Industrial Crops and Products 130:216-229.

Walker KA, Sato SJ (1981). Morphogenesis in callus tissue of Medicago sativa: The role of ammonium ion in somatic embryogenesis. Plant Cell, Tissue and Organ Culture 1:109-121.

Walters DA, Vetsch CS, Potts DE, Lundquist RC (1992). Transformation and inheritance of a hygromycin phosphotransferase gene in maize plants. Plant Molecular Biology 18:189-200.

Wang PC, Zhang J, Sun L, Ma YZ, Xu J, Liang SJ, ... Zhang XL (2017). High efficient multisite genome editing in allotetraploid cotton (Gossypium hirsutum) using CRISPR/Cas9 system. Plant Biotechnology Journal 16:137150.

Wu DR (2001). A study on the niche of dominant species in Phoebe bournei forests in Luoboyan Nature Reserve of Fujian. Acta Ecologica Sinica 21:851-855.

Wu J, Zhang X, Nie Y, Jin S, Liang S (2004). Factors affecting somatic embryogenesis and plant regeneration from a range of recalcitrant genotypes of Chinese cottons (Gossypium hirsutum L.). In Vitro Cellular \& Developmental BiologyPlant 40:371-375.

Wu JY, Huang MJ, Chen MG, Wu Z, Li Y, Liu Q, Cheng Y, Wang XJ (2015). Study on seedling stage growth and early selection of different provenances of Phoebe bournei. Journal of Central South University of Forestry \& Technology 35:1-4.

Zhang K, Wang R, Zi H, Li Y, Cao X, Li D, ... Liu X (2018). Auxin response factor 3 regulates floral meristem determinacy by repressing cytokinin biosynthesis and signaling. Plant Cell 30:324-346.

Zhang L, Zhang Y, Duan RY, Wei XL, Xu XQ (2016). Genetic variation among origin locations of Phoebe bournei (Hemsl.) Yang and a preliminary selection based on seedling growth and root traits. Journal of Nanjing Forestry University (Natural Sciences Edition) 40:33-40. 
Zhang W (2013). The research on germination technology and the fluorescence characteristics of seedlings of Phoebe bournei. Central South University of Forestry \& Technology, Changsha.

Zheng JX, Huang JX, Wang ZZ, Xiong DC, Yang ZJ, Chen GS (2012). Fine root longevity and controlling factors in a Phoebe bournei plantation. Acta Ecologica Sinica 32:7532-7539.

Zimmerman JL (1993). Somatic embryogenesis: a model for early development in higher plants. The Plant Cell 5:14111423.

OPEN ACCESS The journal offers free, immediate, and unrestricted access to peer-reviewed research and scholarly work. Users are allowed to read, download, copy, distribute, print, search, or link to the full texts of the articles, or use them for any other lawful purpose, without asking prior permission from the publisher or the author.

(c) (i)

License - Articles published in Notulae Botanicae Horti Agrobotanici Cluj-Napoca are Open-Access, distributed under the terms and conditions of the Creative Commons Attribution (CC BY 4.0) License. (c) Articles by the authors; UASVM, Cluj-Napoca, Romania. The journal allows the author(s) to hold the copyright/to retain publishing rights without restriction. 